\title{
Simulation of the Governance of Complex Systems (SimCo): Basic Concepts and Experiments on Urban Transportation
}

\author{
Fabian Adelt ${ }^{1}$, Johannes Weyer ${ }^{1}$, Sebastian Hoffmann', Andreas \\ Ihrig $^{2}$ \\ ${ }^{1}$ Faculty of Business and Economics, TU Dortmund University, Otto-Hahn-Straße 4, Dortmund 44227, Ger- \\ many \\ ${ }^{2}$ Faculty of Electrical Engineering and Information Technology, Ruhr-University Bochum, Building ID 04/219, \\ Bochum 44801, Germany \\ Correspondence should be addressed to fabian.adelt@tu-dortmund.de \\ Journal of Artificial Societies and Social Simulation 21(2) 2, 2018 \\ Doi: 10.18564/jasss.3654 Url: http://jasss.soc.surrey.ac.uk/21/2/2.html \\ Received: 27-03-2017 Accepted: 14-01-2018 Published: 31-03-2018
}

\begin{abstract}
The current paper is positioned at the intersection of computer simulation, governance research, and research on infrastructure systems, such as transportation or energy. It proposes a simulation framework, "Simulation of the governance of complex systems" (SimCo), to study the governability of complex socio-technical systems experimentally by means of agent-based modelling (ABM). SimCo is rooted in a sociological macromicro-macro model of a socio-technical system, taking into account the interplay of agents' choices (micro) and situational constraints (macro). The paper presents the conceptualization of SimCo, its elements and subsystems as well as their interactions. SimCo depicts the daily routines of users performing their tasks (e.g. going to work) by choosing among different technologies (e.g. modes of transportation), occasionally deciding to replace a worn-out technology. All components entail different dimensions that can be adjusted, thus allowing operators to purposefully intervene, for instance in the case of risk management (e.g. preventing congestion) or system transformation (e.g. towards sustainable mobility). Experiments with a basic scenario of an urban road transport system demonstrate the effects of different modes of governance (soft control, strong control and a combination of both), revealing that soft control may be the best strategy to govern a complex socio-technical system.
\end{abstract}

Keywords: Governance, Agent-Based Modelling, Complexity, Infrastructure Systems, Transport Network, Transport Mode Choice

\section{Introduction}

1.1 The paper at hand describes a simulation framework that is positioned at the intersection of computer simulation, governance research, and investigation of infrastructure systems. Despite a long tradition of studying the dynamics of social systems by means of computer simulation (Gilbert|2007), the topic of governance of socio-technical systems has not yet been discussed comprehensively (Papachristos 2014). This is all the more surprising if one considers the current debates on climate change and the political efforts to shift the energy system ("Energiewende") or the system of road transportation towards sustainability (Hoffmann et al.|2017). Until now, only few researchers have tackled these issues by means of ABM (cf. Köhler et al. 2009): Mueller \& de Haan 2009: Van Dam et al. 2013.

1.2 Vice versa, governance research in political sciences has only seldom used the method of computer simulation (e.g. Cederman 1997) to investigate the functioning and the effects of governance, but mostly has applied casestudy designs. However, as Edgar Grande (2012) deplores, this strand of research has led to a dead end - still not allowing to understand social mechanisms and system dynamics that produce observable effects (cf. also Torfing et al.2012. 
1.3 Finally, in the engineering sciences, research on infrastructure networks has produced various models of system dynamics, grounded partly on cellular automata concepts (Helbing et al. 2000 Nagel \& Schreckenberg 1992; Selten et al. 2007), partly on agent-based modelling (ABM), e.g. in the case of the transportation simulation frameworks SUMO ${ }^{1}$ Krajzewicz et al.2012) and MATSim² ${ }^{2}$ Horni et al. 2016). The last two models utilise map data of specific regions and fixed travelling plans. Agents' preferences are modelled as well, but only considering time or budget restrictions. MobiTopp, on the other hand, includes destination and mode choice procedures and a route choice algorithm, but no options to influence the system by means of external control (Mallig et al. 2013). In sum, these approaches mostly refer to physical agent models that lack a sociological foundation of action and interaction and do not take into account agents' reaction to different modes of governance. Thus, conclusions on system dynamics and especially system control might be limited.

1.4 The present paper builds upon these three research strands. It adopts the ABM-based approach that the governability of complex socio-technical systems can be investigated experimentally. From governance research, it takes over the idea to contrast self-coordination and control. Finally, from engineering sciences, it incorporates the concept of modelling infrastructures as specific "spaces" that constrain agents' actions and interactions.

1.5 We propose a simulation framework called 'Simulation of the governance of complex systems" (SimCo) to study the governance of complex systems by means of ABM. SimCo is rooted in a sociological model of a sociotechnical system that allows investigating: the decision-making of a large number of heterogeneous social agents; the system dynamics emerging from their interaction; and, finally the impact of different modes of intervention. Like SUMO and other simulation frameworks, SimCo takes into account the spatial dimension of infrastructure systems such as road transportation or energy grids, which also affects decision-making of actors. They act and interact in a network structure with nodes and edges, which is an important boundary condition constraining their choices. Furthermore, these infrastructural constraints can also be used for controlling and steering the system (e.g. by means of road pricing).

1.6 However, socio-technical systems are complex systems that are only partly controllable since a large number of actors act and interact, producing emergent effects at the system level which can hardly be predicted (Coutard 1999. Resnick 1995: Willke 2007). Hence, the main purpose of this paper is to demonstrate that ABM is a useful method to tackle the issue of governability of complex socio-technical systems and thus to stimulate the inconclusive debate which has been going on in sociology and political science for decades.

1.7 After a brief, general introduction of SimCo in Section 2, we will describe the framework in detail by applying it to the case of road transportation in the following sections: An inventory of framework components and their interdependencies can be found in Section 3 , their application to the case of road transportation is described in Section 4, and the model formalisation is covered in Section 5 . The model's implementation, verification and validation are depicted in Section 6, 7, and 8. Finally, using a basic scenario of urban road transport, experiments are conducted in Section 9, testing different modes of governance (soft, strong and combined) and their effects in terms of inducing change towards sustainable mobility, e.g. shifting technology usage or reducing emissions (cf. Banister 2008, Shove 2004).

\section{Scope of the Model}

2.1 SimCo has been conceived as a general-purpose framework that allows to model and to analyse interaction processes in networked systems which force agents to take into consideration the physical infrastructure (with nodes and edges) as an additional variable when making individual choices ${ }^{3}$. It shall improve our understanding of how to control complex, network-like infrastructure systems (macro level) involving the interactions of a large number of strategic decision makers (autonomous agents at the micro level) as a source of complexity Duit et al.2010. SimCo has been designed as a framework to investigate governance issues and to discuss the following two items:

1. Risk management: Operational risk management of infrastructure systems typically aims at reducing undesirable external effects (e.g. pollution) or avoiding system breakdown (e.g. congestion) or even catastrophes (e.g. self-destruction of parts of the system) (cf. Grote 2009).

2. System transformation: Political measures of system transformation typically promote a regime change (e.g. towards sustainable mobility), which mostly entails a fundamental new way of operating the system (cf. Loorbach|2007).

2.2 However, both forms of governance raise the same kind of questions, namely how to control a complex sociotechnical system in a way that helps to achieve intended goals, whether it be risk reduction or system transformation. 
2.3 SimCo shall help to answer the following questions:

- For a given infrastructure system, is it possible to construct a stable base scenario rooted in sociological theory and validated referring to agent and technology types?

- To which extent do different modes of governance (self-coordination, soft control, strong control) affect system performance and support policy goals? ${ }^{4}$

\section{Inventory}

3.1 Road transportation, which serves as an example here, is a complex socio-technical system consisting of different components and subsystems in social and technological areas. These, as well as their interdependencies, will be introduced in this section. A structured, UML-like overview of components and their interactions is depicted in Figure 1

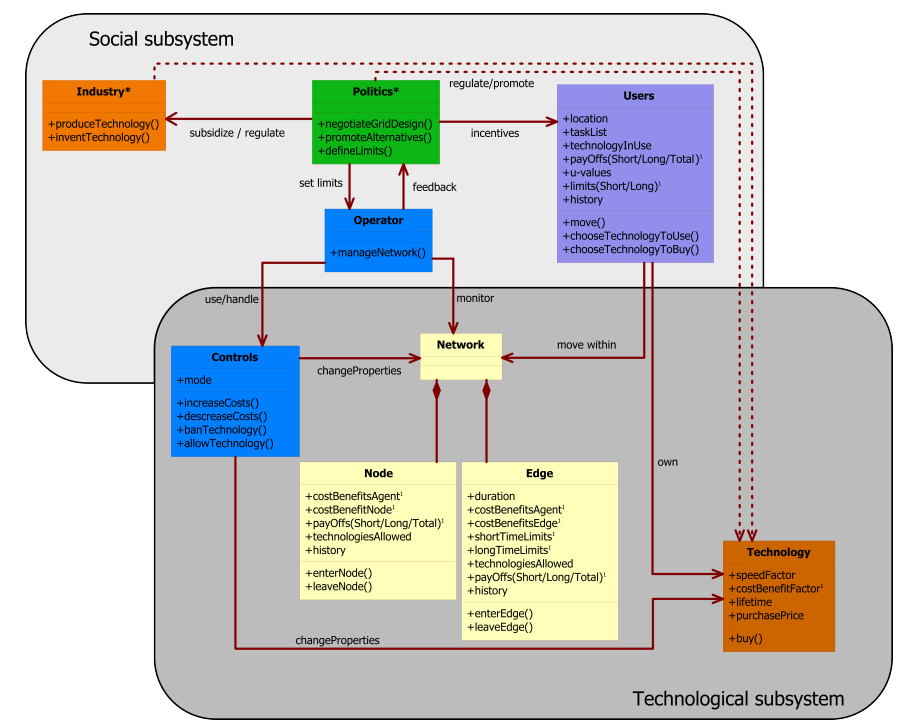

Figure 1: Structural overview of components and interactions (reduced, UML-like diagram, ${ }^{1}$ indicates multidimensional variables; ${ }^{\star}$ not modelled yet).

\section{Social subsystem}

3.2 As in Chappin \& Afman, "the actors in the social subsystem are represented as agents in the model" 2013 , p. 184). The main actor group in road transportation are the users, who move through the network in order to fulfil their tasks (such as visiting distinct nodes). On the basis of bounded rationality, they choose among various transportation technologies (see Section 4.17 for details). Additionally, users periodically decide to invest in new transportation technologies.

3.3 Another important actor is the operator in the control room, who is in charge of monitoring and managing the system, occasionally intervening if certain limits are exceeded. The operator's logic of action is rule-based (for details see Section 4.5).

3.4 SimCo has been conceived as a first step towards modelling the whole social subsystem. The present version consists of the user module and the operator module. It can be complemented by other modules (marked with an asterisk in Figure 1 in future versions, e.g. industrial actors offering established or new technologies. Actors from politics and other stakeholders might also be included, negotiating future policy, deciding on the network topology, setting up regulations (e.g. limits), and providing means for promoting alternative technologies.

\section{Technological subsystem}

3.5 The infrastructure network consists of nodes, edges, and controls, which have various properties such as capacity, costs-of-usage, or technologies-allowed on the respective element. Some of these properties have been 
implemented as multi-dimensional variables with mathematical values, which can be freely defined concerning number and semantics: in the following referred to as "dimensions" (for details see Section 4. SimCo thus allows conceiving edges as roads of a transportation network or as transmission lines of an energy grid. The semantics are scenario-specific ${ }^{5}$.

\section{Nodes}

3.6 Nodes are places with case-specific features making them attractive for agents, e.g. a cinema, a shopping centre or a university. Nodes can either be defined: as "home nodes", where agents live and typically start (and end) their journeys; as "task nodes", where agents travel to in order to fulfil tasks such as working, shopping, learning, relaxing, etc.; or as "standard nodes", which don't possess a specific feature, but only serve as intermediate steps on long distance journeys (e.g. a highway) or as crossing points.

\section{Edges}

3.7 Edges are one-directional connections between nodes allowing agents to move from one node to another in finite time. They also have features that may favour or restrict certain users or technologies, e.g. in the case of bicycle lanes or technology-specific tolls.

\section{Controls}

3.8 Nodes and edges are equipped with controls that allow changing their parameters regarding to different "dimensions". Activating these controls may, for example, lead to banning specific technologies such as conventionally fuelled cars in the case of road transportation.

\section{Technologies}

3.9 Different technologies, such as cars, bicycles, public transport, utilised by users, provided by producers, and regulated by operators and/or governmental activities, are also part of the technical subsystem.

\section{Interactions}

3.10 Interactions ${ }^{6}$ take place at different levels: between social components, between technical components, and between both of them (cf. Chappin \& Afman 2013, p. 185). We will explicate this referring again to the scenario of road transportation.

\section{Social interactions}

3.11 The current version of SimCo puts emphasis on daily practices and routines within infrastructure systems.

3.12 User-user: Users of the infrastructure system interact, for example if they produce a local overload which forces them to change their behaviour (e.g. slow down or take another route). In this respect, in the current version of SimCo, actors react and adapt to others' actions. They do not communicate directly. Instead, their social interactions are mediated by technological subsystems ${ }^{7}$.

3.13 User-operator: Operators and users interact indirectly, as well. Users permanently transmit information (e.g. about their current position) to operators, who in turn try to affect users' choices by changing system parameters (via controls), e.g. blocking streets for conventional cars.

3.14 Other interactions: Users' choices are influenced and constrained by other factors, too, such as the availability of transportation technologies, which in turn is influenced by producers' decisions to invest in certain technologies. Additionally, governmental decisions - e.g. to restrict car use by road pricing or to promote public transport - affect users' choices. 


\section{Technological interactions}

3.15 The system's technological components interact, e.g. by exchanging information, and thus serve as a means of (indirect) social interaction.

3.16 Edge-node: Edges receive information about the identity of adjacent nodes, which can then be transmitted to users on request (see below).

3.17 Technology-edge/node: The properties of edges and nodes determine the technologies allowed. Additionally, the use of technologies changes the state of edges and nodes, e.g. by wearout, tolls paid, or pollutants emitted.

3.18 Controls-edge/node/technology: Controls can affect the current properties of edges, nodes or technologies by charging or limiting their use (e.g. speed limit) or by improving their quality (e.g. investments in public transport).

\section{Socio-technical interactions}

3.19 There are manifold interactions between social and technological components.

3.20 User-node/edge: When visiting nodes (or using edges), users change the state parameters, such as occupancy rate (eventually leading to a traffic jam) or total toll revenue. Additionally, they wear out nodes (and edges) or pollute them, depending on the type of technology used.

3.21 Node/edge-user: The network's physical structure constrains the options available to users, but it also serves as a resource for action. Nodes (as well as edges) provide users with data on request, informing them about: current state, charges, technologies allowed, and their neighbourhood. Furthermore, both nodes and edges pay off ${ }^{8}$, since they may charge users (e.g. toll) or reward them (e.g. salary) depending on different parameters, e.g. the type of node (or edge), the technology used, etc. Users interact with nodes/edges, as individual actions change their state.

3.22 User-technology: Users typically have to decide twice on technologies: first, when they - occasionally - purchase a new device (a car, a bicycle, a monthly ticket for public transport) and, second, when they decide which of the available technologies to use for the next ride.

3.23 Technology-user: Certain technologies allow users to move faster (car) or in a more environmentally friendly way (bicycle), depending on their respective properties.

3.24 Controls-user: Controls affect users, since interventions (on nodes, edges or technologies - see above) change the users' room for manoeuvre.

\section{Concept Formalization}

4.1 "Dimensions" are freely programmable according to the specific scenario selected and will be used for all components of the simulation framework. These features also serve as "levers" for control. Only some variables like technologies' lifetime are mandatory. Thus, "dimensions" can be used to implement specific scenarios without changing the simulation framework as such ${ }^{9}$. The scenario presented in Section 9, for example, uses the dimensions capacity, money, comfort and pollution.

\section{Nodes}

4.2 Network-nodes are distinct spaces with specific features that are attractive for agents and thus are chosen as targets to move to. Nodes are characterised by the following state variables (mostly with several "dimensions"):

- rights of use (determining e.g. technologies-allowed);

- lifetime (which, if exceeded, causes the node to become unusable);

- limits (e.g. maximum carrying capacity, maximum pollution, minimum toll collection);

- payoffs (costs or benefits): to agents who visit the node; to the node visited by an agent ${ }^{10}$; to the system (e.g. the environment, society, etc.), if nodes are used; 
- specific features defining the node's "identity" (e.g. home, task or standard node, or more specifically petrol station, bicycle parking, shopping centre, etc.);

- total payoff for the node over time ${ }^{11}$;

- finally, a memory of previous states.

\section{Edges}

4.3 Network-edges create directed paths between nodes, leaving some potential connections empty. They allow agents to move from one node to another, using specific technologies and paying per use. Edges are characterised by state variables similar to those of nodes, except for their length (i.e. the duration for travelling along the edge).

\section{Technologies}

4.4 To perform their actions, agents use different technologies. These are characterised by the following state variables:

- lifetime, which causes a technology to become unusable once it is reached;

- purchase price;

- a technology factor, which allows to set comparative values for all "dimensions", for example:

- operating costs (especially fees to be paid when using edges or visiting nodes);

- size (i.e. space needed on nodes and edges);

- external effects of use (e.g. pollution or wear out of nodes and edges);

- travelling speed.

\section{Controls}

4.5 Since SimCo has been designed to study the control of complex systems, controllers (be it human probands, artificial control agents or the experimenter) will have the opportunity to intervene both at the operational level of the system management and at the strategic level of the political system.

4.6 Operators can intervene, e.g. by blocking roads, if certain limits are exceeded, which happened for example in Oslo (Norway) and Hagen (Germany) (The Guardian 2017; District Government of Arnsberg 2017). These limits may result from physical constraints (e.g. congestion) or be externally defined (e.g. pollution). Typically, policy plays an important part in defining and adjusting controls, e.g. emission limits, road prices (Transport for London 2017), or subsidies for new technologies ${ }^{12}$. Additionally, policy authorises controllers to operate the system and to intervene by changing parameters for certain "dimensions" of nodes, edges or technologies.

4.7 Control may intend to damp down fluctuation to maintain stability and to avoid risks or a potential breakdown of the system, e.g. in the case of congestion in transportation or blackout in the energy system. However, control may also intend to amplify fluctuation in order to transform the system partly or entirely, e.g. in the case of regime change (cf. Section 2. Controls are characterised by the state variables:

- parameters/“dimensions” to be controlled;

- limits for intervention;

- sensors to monitor system performance;

- governance mode (self-coordination, soft control, strong control).

4.8 Every "dimension" of nodes, edges and technologies can be used as a means of control. This way, controllers may influence the boundary conditions of decision-making of single actors and change their behaviour if they are sensitive to the specific dimension, e.g. costs. 


\section{Short-term and long-term limits}

4.9 In some cases, short-term limits are relevant. For example, in the case of emissions of greenhouse gases by road traffic, only the daily amount of pollution counts (European Parliament 2008, Annex II.A). In other cases, such as road toll, fluctuating short-term data are less important than the total amount over a longer period of time. Consequently, long-term limits are applied.

\section{Modes of governance}

4.10 The intensity of control can vary heavily. Based on our outlook on governance research (Weyer et al. 2015), we identify the following ideal-types:

1. In the mode of self-coordination, agents coordinate themselves following their respective rules of decisionmaking. Operators monitor system operations, prepared to switch to other modes if a critical incident occurs, e.g. exceedance of limits (see below).

2. In the mode of soft control, operators use stimuli or incentives which make certain behaviour attractive or unattractive.

3. In the mode of strong control, operators apply constraints that are more compelling ${ }^{13}$.

4.11 In the current version of SimCo, these modes of governance are implemented as an algorithm (operator agent) that automatically switches interventions off (mode of self-regulation) or on (soft/strong control) if a relevant parameter reaches pre-defined limits (e.g. $60 \%$ of a maximum value for soft, $80 \%$ for strong control). Additionally, in future experiments, suitable interventions may also be triggered by a human proband.

4.12 In the mode of soft control, if a given limit is reached, the use of the particular node or edge is rendered unattractive (e.g. by raising usage fees stepwise) with the expectation that agents will change their behaviour in a way that helps to solve the problem. If the parameter falls below the limit again, the measure will be withdrawn.

4.13 In the mode of strong control, those technologies which do most harm regarding a given parameter (e.g. cars in case of pollution) are banned from the respective node or edge. This measure is directed at prompting agents to change their behaviour so as to avoid a further increase of the parameter values and, ultimately, a total collapse of the node or edge. Afterwards, if the degree drops back below the second limit, the measures will be withdrawn. Of course, soft and strong modes of governance can also be combined.

4.14 The pseudo code (see below) includes the combined type of governance to increase the car's costs of usage if any measurement reaches $60 \%$ of the respective pre-defined limit, and to ban the car completely if $80 \%$ are exceeded:

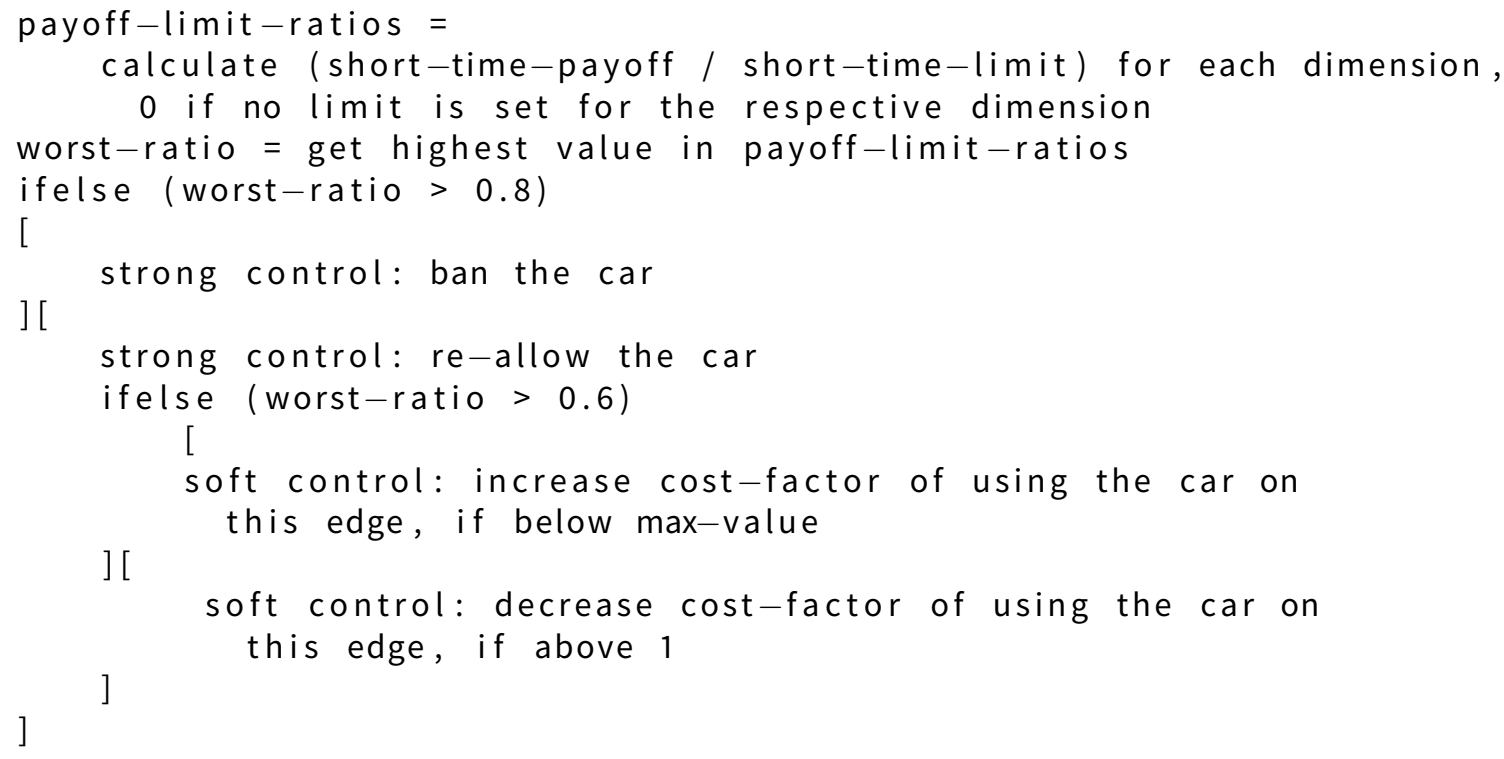




\section{Agents}

4.15 User-Agents ${ }^{14}$ move through the network, which both enables and constrains their actions, to fulfil their tasks. They select edges that lead to nodes with a high utility when making decisions, using technologies that fit their interests best.

4.16 Agents are designed according to sociological theory of action. In modelling decision-making, we lean on the "model of sociological explanation" (MSE) by Hartmut Esser (1993), which explains structural dynamics of social systems by means of a macro-micro-macro model similar to Coleman's "boat" (1990). This model describes system dynamics as the emergent result of actors' interactions (micro-macro link), which on their part are constrained by the current state of the system (macro-micro link). Other concepts such as Ostrom's Institutional Analysis and Development (IAD) framework operate rather similarly (Ghorbani et al. 2013: Ostrom 2010), pointing to the heterogeneity of actors and their choices.

4.17 According to these models, actors' choices are shaped by their individual perception of situational constraints as well as their individual preferences. Actors make decisions with bounded rationality, referring to multiple evaluation criteria (cf. the MAUT model of Velasquez \& Hester 2013$)^{15}$. Behavioural alternatives are evaluated by assigning a utility to every possible consequence and finally choosing the option with the highest subjective expected utility (cf. Konidari \& Mavrakis 2007, p. 6246). The evaluation of subjective expected utilities (SEU) may be calculated with the following formula, including action alternatives $(A)^{16}$, the valuation $(U)$ of expected outcomes $(\mathrm{O})$ and the expected probability $(\mathrm{p})$ of achieving a goal $(\mathrm{O})$ by taking an action $(\mathrm{A})$ :

$$
S E U\left(A_{i}\right)=\sum_{j=1}^{n} p_{i j} * U(O)_{j}
$$

4.18 As Esser (2000, p. 250) points out, this calculation is based on subjective evaluations, which may explain why various actors behave differently in identical situations. In addition, many everyday decisions are based on routine action, which is not calculated reflexively (Kroneberg 2014).

4.19 In our adaptation of the SEU model, the probabilities ( $p$ values) are not fixed but based on situational factors (i.e. current financial resources of the respective agent, traffic situation, etc.) as well as transport mode characteristics (cf. Section 8.10). Furthermore, agents may select the second-best choice if its SEU value is not too far below the best choice, representing a "fuzzy logic" option (Kron 2006.

4.20 In the SimCo framework, different types of agents can be created by taking a generic agent and adjusting parameters such as individual preferences and valuation of goals.

4.21 User-agents are characterised by the state variables:

- location (the current node or edge);

- list of task-nodes still to be visited;

- technologies available;

- technology currently used;

- individual preferences (type-specific valuation of goals, e.g. travelling fast, cheap, eco-friendly and/or comfortable);

- limits, e.g. concerning bank account and range of sight;

- payoffs from actions (current/total);

- resources needed to perform actions (modelled combining payoffs and limits);

- finally, a memory of visited nodes and edges, technologies used and results of SEU calculations.

\section{Model Formalization}

5.1 Since all components and concepts of the model have been introduced, the complete model can be set up. This contains several interconnected loops. 


\section{Setup of the system}

5.2 The initial setup of the system comprises (according to the specific scenario):

- the setup of the network with nodes, edges, and controls;

- the setup of several types of technologies; and, finally,

- the setup of various types of agents with heterogeneous preferences, located at different nodes and equipped with a variety of technologies and individual task lists.

\section{First loop: Agents' routine choices}

5.3 Agent' choices can be divided into regular, partly routine-based decision-making and a periodical/occasional decision to replace the currently used technology (second loop, cf. Section 5.8).

5.4 Agents start their journeys at their respective home node, referring to an ordered task list (such as kindergarten, work, shopping, home). As depicted in blue in Figure 2 they first select the next target node and then decide to which node to go next ${ }^{17}$. According to their individual preferences, they choose one of several alternatives available that best fit their interests.

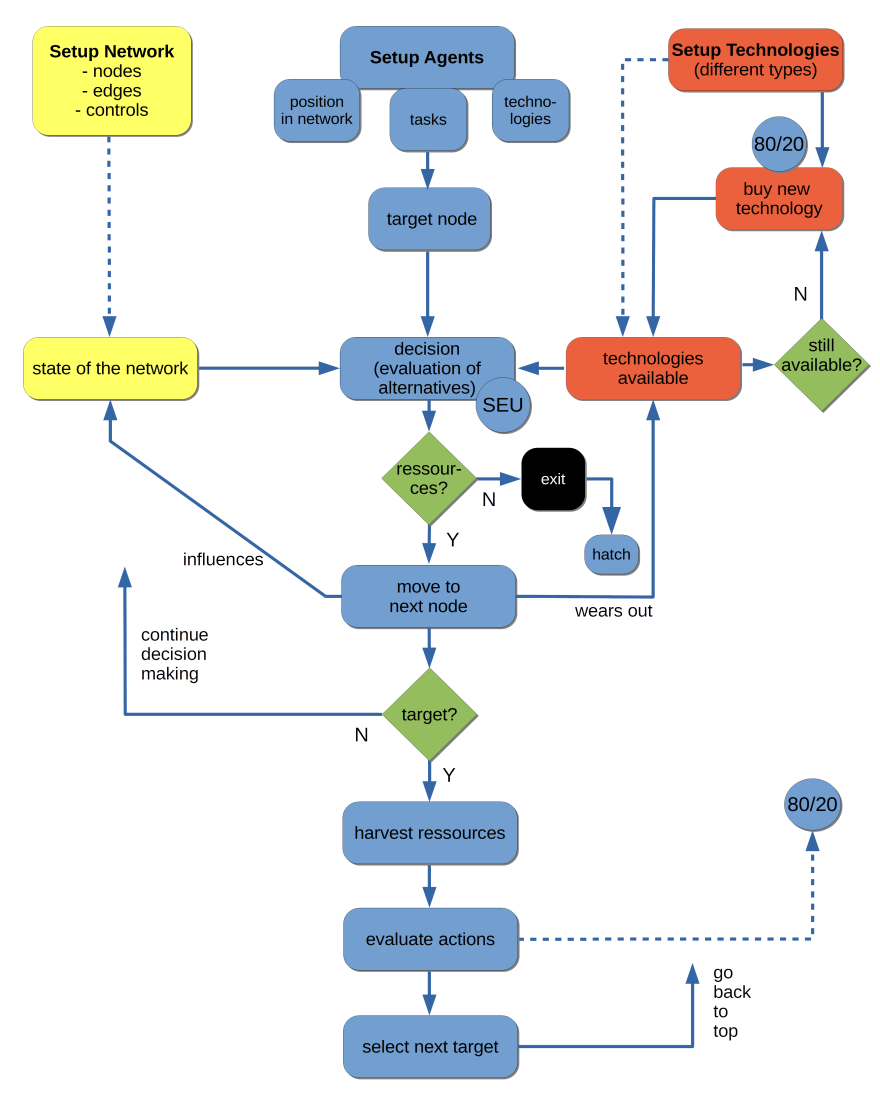

Figure 2: Flow chart of agent's choices (first and second loop).

5.5 The pseudo code below highlights the main steps of the decision process. If, for example, two follow-on nodes can be reached by means of two technologies, four alternatives open up via combinatorial logic. The value of each alternative depends on the value of the respective node (i.e. its costs and benefits in "dimensions" connected to the agent's preferences) and the value of the edge (mainly its costs and length) leading to it, which both, however, may differ according to the type of technology used and to the valuation of conflicting preferences by the agents (e.g. move fast or cheap). According to our sociological model of action (cf. Section 4.17), agents' choices are also influenced by the amount of resources left and the current state of the network that changes dynamically (due to agents' actions), resulting in different decisions of various agents at different points in time (e.g. using the bicycle or the car). 


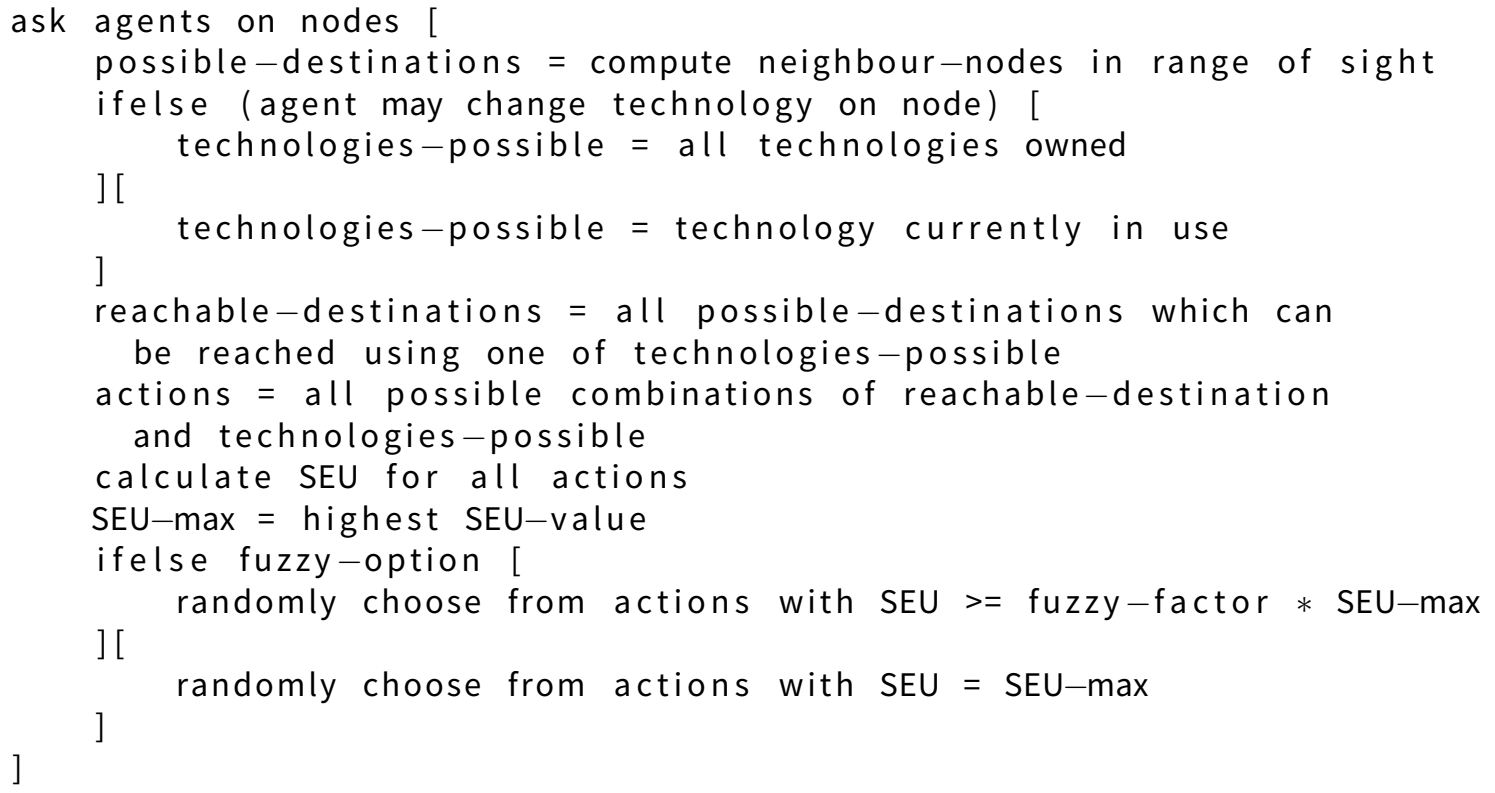

5.6 The first loop takes place in steady time steps ("ticks") ${ }^{18}$. Agents continue this procedure until they have reached the target, where they can harvest the respective resources. They evaluate their performance by memorizing the technology used and other performance parameters and then select the next target node from their task list.

5.7 There is also a learning mechanism, though not at the level of the single agent, but only at the level of the whole population: Agents that lack resources for performing actions will exit the simulation, and a new agent will hatch automatically, equipped with the properties of one of the remaining agents, who is selected by chance. In the long run, successful types of agents will thus have higher chances of being used as a source for hatching ${ }^{19}$.

\section{Second loop: Replacement of technology}

5.8 If the technologies available to the agent have reached their limits and are worn-out, they have to be replaced (see Figure 3, red colour). For modelling these purchase decisions, we use a provisional eighty-twenty-rule: In $80 \%$ of all cases, agents purchase the most successful technology, i.e. the one they mostly selected in their daily choices until then. However, in $20 \%$ of all cases, they opt for a type of technology they didn't possess before, if available. By this means, new technologies may "invade" the market and replace old ones step-by-step, if successful. The second loop is called up if specific limits, such as the lifetime of technologies, are exceeded.

\section{Third loop: System management (and infrastructure policy)}

5.9 The operators monitor the state of the network and intervene if certain limits are exceeded, typically based on a political decision to operate the system within defined limits (e.g. pollution, congestion). Operators evaluate the system's performance and adjust parameters of different "dimensions" 20 . In this way, they indirectly affect agents' decision-making by changing the boundary conditions. Different modes of governance may be applied here (cf. Section 4.5). Additionally, the network's performance data are reported to politics and may trigger political negotiations, e.g. on redesigning the network, reconfiguring controls and incentives, or promoting alternatives $^{21}$.

\section{Software Implementation}

6.1 The model was programmed in NetLogo (Wilensky 1999), thus using standard software for designing sociological experiments by means of $\mathrm{ABM}^{22}$. 


\section{Simulating networks using NetLogo}

6.2 Like Sugarscape and other models of artificial societies (Epstein 2006; Epstein \& Axtell 1996, Krusch 2008), SimCo depicts the interactions of a large number of heterogeneous agents in an artificial scenario. However, in contrast to these models, the artificial world is not a chessboard-like lattice allowing agents to move arbitrarily to one of eight neighbouring fields, but a network-like structure with a limited number of paths to choose from and to follow (cf.Wilensky|2007).

6.3 Compared to network models in sociology (Jansen \& Diaz-Bone 2011) and agent-based models such as "Diffusion on a Directed Network" (Stonedahl \& Wilensky 2008) or "Page Rank" (Stonedahl \& Wilensky 2009), edges in SimCo do not connect nodes virtually, but are conceived as (edge-)agents with a spatial dimension and other features, such as carrying capacity. Agents need time to traverse edges and interact with them in various ways - similarly to agents and patches in NetLogo.

6.4 We used a link-breed to model edges, which allows specifying characteristics of an arbitrary number of "dimensions", as described in Section 3.5. Furthermore, we implemented functions to handle the interactions between agents and nodes/edges, as they need to know of each other. As an interaction outcome, we mainly have to calculate payoffs. Since we organised the different "dimensions" modelled within a scenario in the same way for all components, this can be easily done via list operations such as "map".

\section{Scenario generator}

6.5 A separate NetLogo model facilitates setting up scenarios. It allows users to choose from a predefined set of nodes, edges, agents and technologies, and to save this configuration as a master file (allowing to rerun scenario generation when type definitions have changed) and as a SimCo network file which can be loaded into SimCo afterwards. The two models share some basic code.

\section{Output organization}

6.6 SimCo entails some basic plots in its graphical user interface, showing for example the percentage proportion of technologies used or the number of agents unable to move due to local restrictions. The main visualisation (cf. Figure 3 shows the network and, using a colour code, its state with regard to different "dimensions" specified in the scenario.
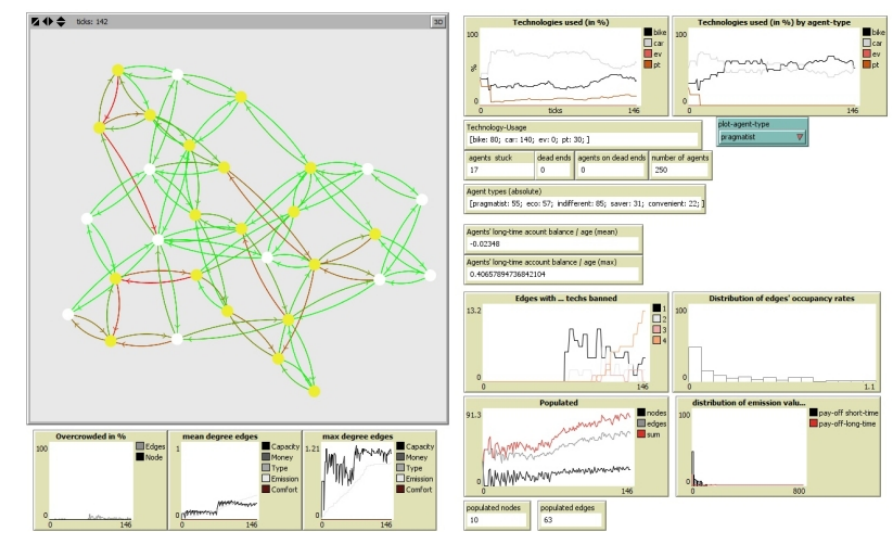

Figure 3: Screenshot (small example network with 30 nodes).

6.7 Besides, we collect many data from test runs, such as information on agents' choices, nodes' and edges' state variables as well as the history of controlling interventions. Most of these data are collected using the stats extension ${ }^{23}$ and can be exported in single CSV files on request. Result files are processed using standard tools to extract only relevant variables and, finally, data is imported to SPSS in order to calculate and evaluate results at both the system and the agent level. 


\section{Interface for human probands}

6.8 The model was implemented to be run in GUI mode in order to conduct experiments with human probands, who can control the system and intervene if necessary. Additionally, Netlogo's headless mode allows conducting automated experiments without any user or experimenter interaction, which can be used to test basic functions or to calibrate scenarios.

\section{Model Verification}

7.1 Model verification on a technical level was mainly focused on interaction functions, thus ensuring that costs and benefits of agents' actions are calculated correctly and changes in state variables function as intended. Furthermore, calculating the subjective expected utility value for actions was tested and improved step-by-step in order to avoid flawed outcomes. This included the exemplary comparison of situational input parameters, their processing within agents' decision-making, and, finally, results of agents' SEU calculation. In some situations, several options showed up with the same, highest subjective expected utility value: Agents selected from them in a fixed order such that the first action under consideration gained a structural advantage. Randomization helped to avoid this inappropriate decision-making.

\section{Model Validation}

8.1 The SimCo framework offers a large variety of options to construct scenarios of socio-technical infrastructure systems and to conduct experiments with different settings. In the following, we will introduce a basic scenario representing the current state of urban road transportation, which was validated by various tests and, subsequently, has been used to conduct experiments on regime change (cf. Section 9).

8.2 As criteria of internal validation, we set the following requirements:

- Agents should have a chance to survive, i.e. by acting more or less "cost-covering" without exceeding their cost limits ${ }^{24}$.

- The number of agents leaving the simulation should remain low ${ }^{25}$.

8.3 Additionally, we performed an external validation ${ }^{26}$ :

- Agents' decisions concerning technology usage should roughly match empirical data on modal split ${ }^{27}$.

- Composition of edge types should roughly resemble a typical mid-sized town in Germany.

\section{Parameter variation}

8.4 We ran repeated experiments with multiple parameter variations and analysed them using the above-mentioned measurements ${ }^{28}$. Parameter variations encompassed the following items:

- Payoffs agents gain if reaching task nodes ("payoff-task" - variation from 3 to 12).

- A strong limit, causing agents to leave the simulation if exceeded ("strong-limit-money" - variation from -700 to $-1,000)$.

- A soft limit, influencing agent behaviour concerning cost sensitivity in the short run ("soft-limit-money" variation of "daily debt" limit from -10 to -60).

- A financial "buffer" value to evaluate the feasibility of the next action ("financial-cushion" - variation from 3 to 15$)$.

Furthermore, we tested two different network structures, composed of five types of edges, namely

- "shared-big" and "shared-small", which can be used by every mode of transport and merely differ regarding their capacity; 
- "car-only", "bicycle-only", "public-transport-only", which can only be used by a single mode of transport and have the same capacity as "shared-big".

8.5 In order to examine if the composition of edges matters, we first constructed an artificial network containing only one single type of edge ("shared-big") on which all technologies may be used without restrictions. Next, we tried to reproduce a more realistic network by 'translating' real-world data from a typical medium-sized German city (City of Dortmund 2004) into SimCo-related parameters, especially the shares of node and edge types $^{29}$.

8.6 In combination with two random seeds ${ }^{30}$ used to generate the SimCo network files, we thus investigated four different networks by conducting identical parameter variation, as presented above ${ }^{31}$. After a large number of experiments, the combination (4, -900, -50, 3; cf. Table 4 proved to be optimal across all network structures. The realistic network provided better fitting results regarding our requirements specified in Section 8.3. The resulting basic scenario (with a realistic network topology), used for experimentation in Section 9 , is summarised in Table 4

\section{Agent types and technology factors}

8.7 In order to calibrate agent behaviour, a survey on the selection of transport modes in urban areas was conducted and provided empirical data on individual preferences. Respondents were asked to evaluate different goals such as travelling cheap, fast, or eco-friendly - and, based on their replies, were clustered to allow determining the respective shares of actor types.

8.8 The resulting five types of actors, which roughly conform with other studies (Dijk \& Kemp 2010; Götz 2007), as well as their preferences are listed in Table 1. "Pragmatists" mostly favour travelling fast, while "ecos" prefer eco-friendly and affordable transportation. "Penny-pinchers" like travelling cheap and fast, while "convenient" actors favour comfortable transportation. Only "indifferent" agents do not show specific differences in their preferences. By implementing these actor types into agent types, we added heterogeneity to our scenario.

\begin{tabular}{lccccccc}
\hline \multirow{2}{*}{ Actor Types } & \multicolumn{5}{c}{ Preferences } & \multirow{2}{*}{ N } & \multirow{2}{*}{ Share } \\
\cline { 2 - 5 } & Cheap & Fast & Eco-friendly & Comfortable & & \\
\hline Pragmatic & 3.7 & 6.8 & 2.4 & 1.2 & 119 & $24 \%$ \\
Eco & 4.4 & 2.0 & 7.6 & 1.9 & 123 & $24 \%$ \\
Indifferent & 4.0 & 4.6 & 2.8 & 4.2 & 157 & $31 \%$ \\
Penny-pincher & 9.0 & 4.7 & 3.7 & 0.7 & 58 & $11 \%$ \\
Convenient & 0.6 & 6.4 & 0.2 & 6.8 & 49 & $10 \%$ \\
& & & & & 506 & $100 \%$ \\
\hline
\end{tabular}

Table 1: Preferences of actor types (mean values - ranging from 0 to 10) (Source:Teigelkamp 2015).

8.9 The sociological concept of governance assumes that various types of actors will react differently to incentives and restrictions. In order to investigate the influence of various agent populations on the effectiveness of governance modes, we constructed three different sets of agents. First, an artificial set with an equal distribution of agents. Second, a set based on the shares observed in our survey. However, shares of agent types in the survey were heavily biased towards ecologically oriented users ("ecos"), preferring the bicycle, which led to a rather unusual modal split in our simulation. Hence, we created a third "realistic" set (cf. Table 2 which better fits the real distribution of agent types concerning modal split (cf. Meißner 2014) and was later used for experimentation. Nevertheless, we accepted the respective preferences from the survey data. 


\begin{tabular}{|c|c|c|c|c|}
\hline & & \multicolumn{3}{|c|}{ Number of agents } \\
\hline \multicolumn{2}{|c|}{ Agent-set } & Artificial & Survey-based & Realistic \\
\hline \multirow{6}{*}{ Agent types } & Pragmatic & 1,200 & 1,440 & 750 \\
\hline & Eco & 1,200 & 1,440 & 450 \\
\hline & Indifferent & 1,200 & 1,860 & 1,350 \\
\hline & Penny-pincher & 1,200 & 660 & 450 \\
\hline & Convenient & 1,200 & 600 & 1,500 \\
\hline & Sum & 6,000 & 6,000 & 6,000 \\
\hline
\end{tabular}

Table 2: Agent-sets.

8.10 To calibrate technologies, respondents were asked to assess different modes of transport - especially regarding their suitability for achieving certain goals (cf. Table 3 ).

\begin{tabular}{lcccc}
\hline \multirow{2}{*}{ Technology } & \multicolumn{4}{c}{ Preferences } \\
\cline { 2 - 5 } & Fast & Cheap & Eco-friendly & Comfortable \\
\hline Public transport & 3.15 & 4.85 & 6.28 & 3.67 \\
Bicycle & 4.06 & 8.94 & 9.32 & 3.30 \\
Car (fossil-fuelled) & 6.08 & 3.00 & 1.96 & 6.72 \\
Electric vehicle & 7.80 & 6.08 & 7.64 & 7.78 \\
\hline
\end{tabular}

Table 3: Respondents' assessment of different technologies regarding the achievement of goals (ranging from 0 to $10 ; N=506$ ) (Source: Teigelkamp 2015).

8.11 The resulting "technology factors" were included as part of the agents' decision-making: They are multiplied by the respective base payoffs of nodes and edges and thus influence the achievement of goals, for example concerning moving fast or eco-friendly through the transportation network (cf. Section 4.4). Consequently, technologies' characteristics in the SimCo framework are based on the subjective, perceived costs and gains rather than objective data, which are usually used in ABM (cf. Köhler et al.|2009: Lopolito et al.|2013). However, test runs yielded some unexpected results since an unrealistically large proportion of agents used the bicycle (cf. Lürwer \& Meißner 2013) on typical modal split). Obviously, on the respondents' side, there is a certain bias which mentally frames real, everyday decisions, but remains in the background when people are interviewed. Especially routines, which are deeply embedded in social practices and guide everyday decision-making, are an important factor to consider when explaining deviations between real behaviour and survey-based attitudes (Elster|2016: Kroneberg 2014).

8.12 The SEU model presented in Section 4.17 allows integrating these routines by adding additional preferences to the decision-making algorithm, namely travelling "by car", "by public transport", or "by bicycle" in complement to travelling "fast", "cheap", "comfortable", or "eco-friendly". By implementing these "hidden preferences", the use of certain technologies becomes more likely, regardless of situational parameters. This addition allowed us to maintain the core structure of the SEU model while simultaneously implementing a more realistic representation of daily routines into agents' behaviour.

\section{Final setup}

8.13 The final basic scenario, which runs stable and will serve as a reference point for experiments with different governance scenarios, consists of the following elements and proportions: 


\begin{tabular}{llc}
\hline & Type & Number/value \\
\hline \multirow{4}{*}{ Nodes } & Home & 204 \\
& Task & 236 \\
& Standard & 160 \\
\hline \multirow{4}{*}{ Edges } & Shared-small & 984 \\
& Shared-big & 110 \\
& Car-only & 104 \\
& Bicycle-only & 3 \\
& PT-only & 110 \\
\hline \multirow{4}{*}{ Users (realistic agent-set) } & Pragmatic & 750 \\
& Eco & 450 \\
& Indifferent & 1,350 \\
& Penny-pincher & 450 \\
& Convenient & 1,500 \\
\hline \multirow{4}{*}{ Parameters } & Payoff-task & 4 \\
& Soft-limit-money & -50 \\
& Strong-limit-money & -900 \\
& Financial-cushion & 3 \\
\hline
\end{tabular}

Table 4: Final basic scenario.

8.14 In the realistic scenario, the distribution of 600 nodes and 1,311 edges is based on data from a typical mid-sized German town. Concerning the agent set, the realistic distribution is chosen, correcting biases in the survey data and including mental frames. Finally, relevant parameters are adjusted based on our parameter variation.

\section{Experimentation}

9.1 Experimentation with SimCo has first put emphasis on the network of road transportation and the issue of regime change ${ }^{32}$, which has been analysed from the angle of governance research, focusing on the impact of different modes of governance. Experiments included a reference scenario (without any intervention) and three governance scenarios with different degrees of intervention. The latter three focus on cars with internal combustion engine and assume (without debating in detail) that this technology is more harmful for the environment than other technologies, e.g. considering its $\mathrm{CO}_{2}$ emissions.

9.2 These three governance scenarios were implemented as follows:

- Soft control: via road pricing, limited in space and time ${ }^{33}$. Costs of agents using the car are raised stepwise if traffic jams occur or pollution exceeds limits, and lowered again afterwards.

- Strong control: via spatial and temporal car bans if a second limit is reached (cf. Section 4.5). Agents are forced to change technology or take another route.

- Combination of soft and strong control.

9.3 The effects of interventions were measured by means of various indices (cf. Table[5): mean capacity utilisation on edges, mean degree of emission on edges in short-time ("days") and long-time ("months"), and technology usage (bicycle, car, public transport). 


\begin{tabular}{lllllll}
\hline & $\begin{array}{l}\text { Mean } \\
\text { capacity } \\
\text { utilisation } \\
\text { on edges* }\end{array}$ & $\begin{array}{l}\text { Mean emis- } \\
\text { sion short- } \\
\text { time* }\end{array}$ & $\begin{array}{l}\text { Mean emis- } \\
\text { sion } \\
\text { time* }\end{array}$ & $\begin{array}{l}\text { Bicycle } \\
\text { long- }\end{array}$ & Car usage & $\begin{array}{l}\text { Public } \\
\text { transport } \\
\text { usage }\end{array}$ \\
\hline $\begin{array}{l}\text { Self- } \\
\text { coordination } \\
\text { (reference }\end{array}$ & $21.36 \%$ & $17.96 \%$ & $33.28 \%$ & $31.61 \%$ & $62.45 \%$ & $5.94 \%$ \\
scenario) & & & & & & \\
\hline Soft control & $\mathbf{1 5 . 7 9 \%}$ & $\mathbf{1 2 . 7 6 \%}$ & $\mathbf{2 4 . 6 6 \%}$ & $46.05 \%$ & $\mathbf{3 7 . 4 8} \%$ & $\mathbf{1 6 . 4 7 \%}$ \\
\hline $\begin{array}{l}\text { Strong } \\
\text { control }\end{array}$ & $19.13 \%$ & $15.55 \%$ & $\mathbf{2 8 . 9 2 \%}$ & $41.44 \%$ & $52.08 \%$ & $6.47 \%$ \\
\hline $\begin{array}{l}\text { Soft/strong } \\
\text { (combined) }\end{array}$ & $16.37 \%$ & $12.88 \%$ & $\mathbf{2 4 . 6 5 \%}$ & $\mathbf{4 9 . 9 4 \%}$ & $38.95 \%$ & $11.10 \%$ \\
\hline
\end{tabular}

Table 5: Results of governance experiments ( ${ }^{*}$ percentages of respective limits).

9.4 As Table 5 shows, we achieve the desired effects with all three modes of governance: a decrease of car use, an increase of bicycle and public transport usage, and - triggered by these changes - also a reduction of capacity utilisation and emissions. Additionally, as bold numbers show, soft control mostly performs best (or closely second best). This confirms previous experiments with the simulation framework SUMO-S (Adelt et al. 2014). Only in two cases, the combination of soft and strong control yields slightly better results. But, obviously, political goals of regime change in mobility can best be achieved by relying only on soft measures of intervention.

9.5 Figure 4 again demonstrates the varying impact of different modes of governance: The reference scenario remains stable over 8,000 ticks, as does the strong control scenario, in which values rapidly adjust after a few ticks to a level that remains stable in the long run, albeit fluctuations in the short run (e.g. as short-term reactions to bans, with return to the original behaviour after the ban is lifted).

9.6 Soft control has the highest impact in terms of long-term learning. In spite of short-term fluctuations, in the long run, agents change their behaviour remarkably in favour of more sustainable modes of transport. Surprisingly, the result of combining soft and strong control is so similar to soft control that it seems advisable to refrain from resorting to strong measures as a means of regime change.

9.7 Finally, Figure 5 may offer a possible explanation for the sudden switch at about 1,000 ticks. At this point in time, the composition of the agent-population suddenly changes. Agents insisting to use the car even in high-price situations (provoked by soft measures such as tolls) run into financial problems and exit the simulation. As a result of this persistence, the learning algorithm on the population level (see Section 5.7) triggers a slow, but gradually accelerating change in proportions of agents and then - as a consequence - of technologies' usage as well. Again, this mechanism can be observed most clearly in the soft control scenario. 

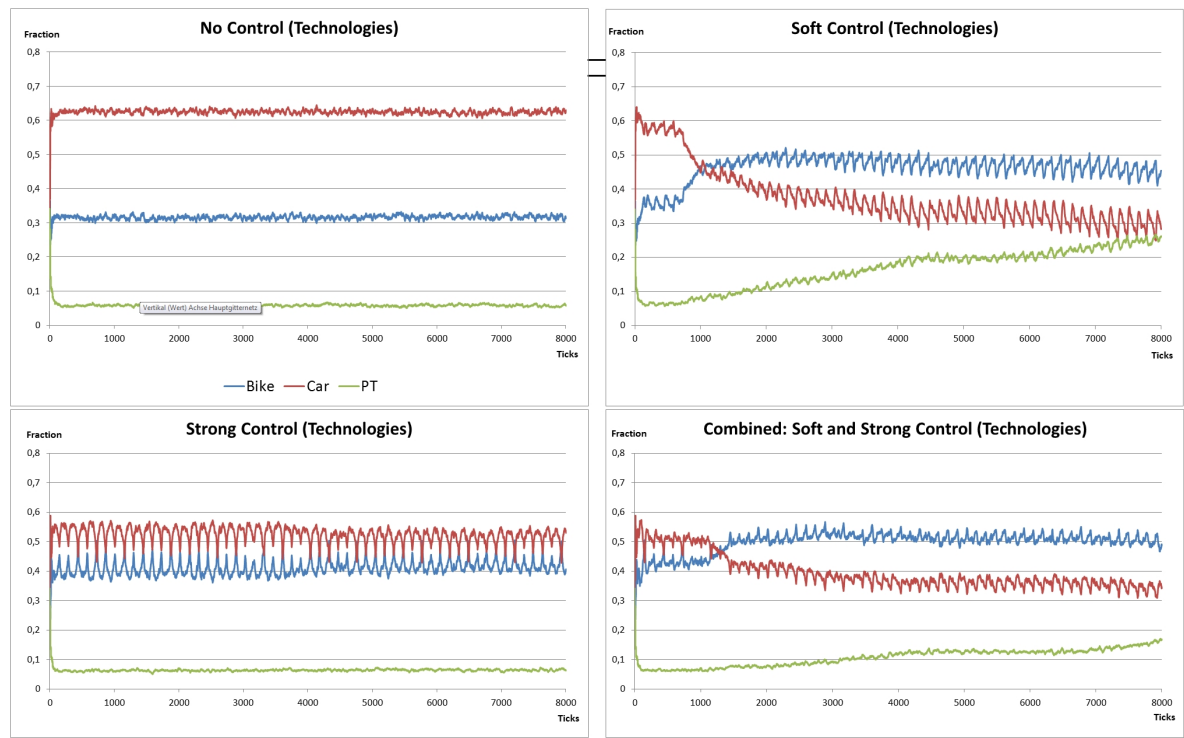

Figure 4: Technology usage (fraction) in course of time (8,000 ticks).
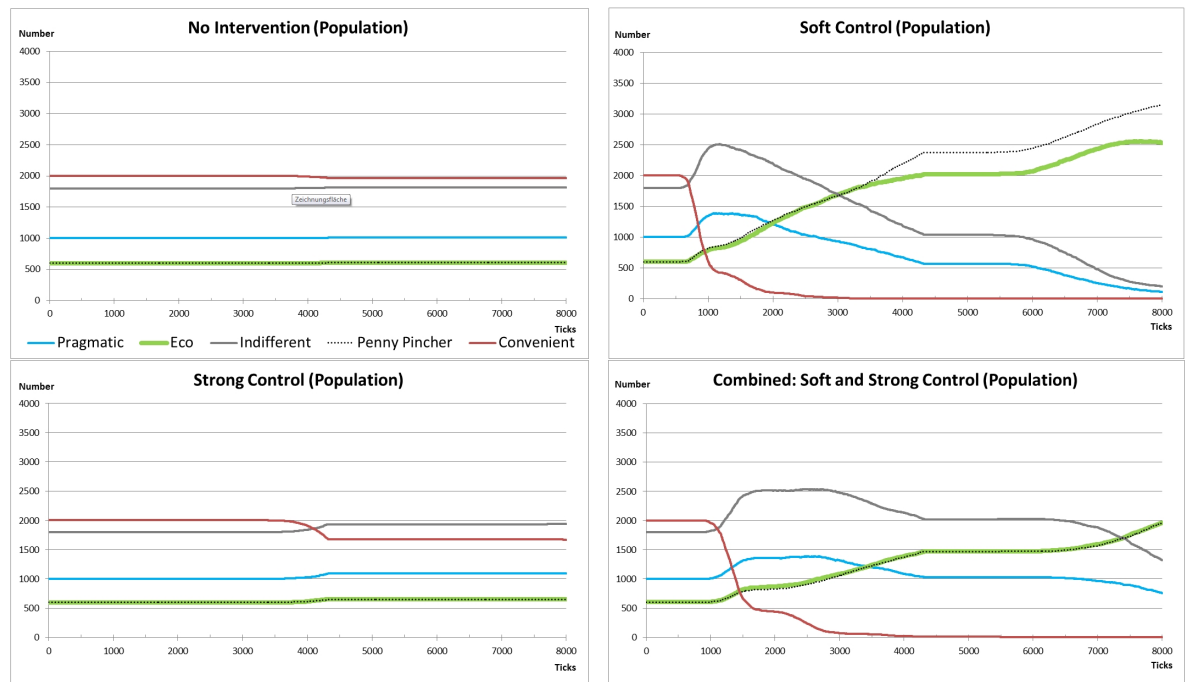

Figure 5: Agent population (total) in course of time (8,000 ticks).

9.8 Summarizing these results, one could argue that soft control is the most effective mode of governance, leading mostly to the best results with lower efforts, compared to the combination of soft and strong control. The environmental benefits are remarkable, but social acceptance might be a problem, since many agents have been forced to leave the simulation due to financial restrictions.

\section{Conclusion}

10.1 This paper has presented the implementation of a model of a socio-technical system, that builds upon governance research, transportation research and computer simulation. Sociological theory of action helps to conceptualise agents' decision-making (micro) and system dynamics (macro), while survey data allow distinguishing different agent types with specific preferences.

10.2 The simulation framework is free of semantics and thus allows developing different scenarios. A basic scenario of urban road transportation has been developed, the stability and reliability of which has been tested by means of parameter variation with data from a medium-sized German town and survey data. 
10.3 SimCo allows to investigate the issue of governability of complex socio-technical systems experimentally - referring either to the case of risk management or to the case of regime change. We performed experiments on the latter issue and confirmed previous findings (Adelt et al.|2014), indicating an impact of every mode of control in terms of promoting sustainability. However, once again, soft control performed better than strong control (or the combination of both modes of governance) in achieving policy goals, the legitimacy of which we simply took for granted.

\section{Limitations and Further Perspectives}

11.1 SimCo has been designed as a tool for the analysis of governance issues that can hardly be investigated in the real world. It aims at advising stakeholders from politics and the civil society, but also at stimulating the governance debate in sociology and political science.

11.2 Until now, SimCo has been limited to one basic scenario and has not yet proven its utility as a multi-purpose tool for different scenarios (e.g. in the energy sector). Additionally, it is rooted in a specific sociological macro-micromacro theory that might be challenged by other models. Some modules (transport companies, technology producers, etc.) are still missing. Furthermore, we did not yet conduct experiments with human probands, trying various control options (see Section 4.5) to foster change or ensure stable operation of the system.

11.3 Further work and further experiments will explore these issues in more depth; they will also tackle various scenarios and what-if questions and will examine the issue of resilience (recovery in case of disturbance). SimCo can serve to evaluate to which extent the network topology or the composition of the agent population affect the performance of different modes of governance. Furthermore, sensitivity analysis should be conducted to test the impact of some assumptions we made concerning limits used as input for the controlling algorithms as well as agents' purchase decisions (see Section 5.8).

11.4 Additionally, further research could complement the framework with additional modules, e.g. a producer module bringing into play new technologies created by innovators and/or promoted by politics.

\section{Notes}

${ }^{1}$ Simulation of Urban MObility.

${ }^{2}$ Multi-Agent Transport Simulation.

${ }^{3}$ The following sections use the ODD protocol Grimm et al.|2006, 2010 in the adapted version of Van Dam et al. (2013). For more details, see also SimCo's webpage at http://simco.wiwi.tu-dortmund.de/

${ }^{4}$ In future work, SimCo might also serve to determine to which extent network topology and/or the composition of the agent population affect the performance of different modes of governance.

${ }^{5}$ We decided to develop this open configuration without semantic meaning in order to use SimCo as a general tool for different research projects and to allow for focussing on basic - and still unresolved - issues of governance research.

${ }^{6}$ On a general level, the term interaction can be defined as mutual or reciprocal action or influence by means of a common definition of the situation (Esser 2000, p. 17f.).

${ }^{7}$ Bruno Latour (2007) argues that modern societies mostly communicate and interact by means of technology - in contrary to primates, which communicate directly via physical contact.

${ }^{8}$ Pay off can include positive as well as negative values and is not restricted to the monetary dimension. It can, for example, be used to model pollution, which may be limited on an individual basis.

${ }^{9}$ Implemented as arrays, we can calculate e.g. costs and benefits of agents' actions independent from the actual number of dimensions. Using special variables for each dimension would result in re-implementation work each time a dimension is added to or removed from the model.

${ }^{10}$ Costs and benefits of nodes must not be identical to those of the agent, e.g. in case of fees, the agent has to pay the node.

${ }^{11}$ The total payoff is calculated by adding all gains and losses over time, resulting from the given costs and benefits and occupancy rate by agents. 
${ }^{12}$ Since the political system is not yet part of the simulation framework, the experimenter will specify this input at present.

${ }^{13}$ However, control must not be confused with coercion. Even in the case of strong control, actors still have some degree of choice between alternatives.

${ }^{14}$ In the present version of SimCo, only agents of type "user" and "operator" are implemented.

${ }^{15}$ See Schlüter et al. (2017) for a classification of various agent models.

${ }^{16}$ In our implementation, an action includes the route (nodes/edges) as well as the technology to be used.

${ }^{17}$ If they cannot reach the target node directly, they choose the best intermediate node available.

${ }^{18}$ In our scenario, 144 ticks virtually represent one "day", and 4320 ticks one "month".

${ }^{19}$ We opted for this kind of evolutionary mechanism because its implementation is much more manageable than an algorithm with individual learning.

${ }^{20}$ The algorithm for "automated control" introduced in Section 4.11 behaves the same way.

${ }^{21}$ However, this feedback loop is not currently implemented in SimCo.

${ }^{22}$ The complete software code can be found at openABM: https://www. comses.net/codebases/5924/ releases/1.1.0/.

23 https://github.com/cstaelin/Stats-Extension/.

${ }^{24}$ Mean "money" payoffs, normalised by lifetime, should be between -0.15 and 0.15 .

${ }^{25}$ Share of agents leaving the simulation due to exceeding financial limits should be smaller than $10 \%$ for each agent type.

${ }^{26}$ Readers should take into account that SimCo has not been designed to perfectly reproduce a realistic scenario, but to investigate more general issues of governance research.

${ }^{27}$ Data on mean technology usage per agent type were taken from a survey; cf. Section 8.7

${ }^{28}$ We adapted a script by Lukas Ahrenberg to conduct the large number of experiments in parallel on a computer cluster (https://github.com/ahrenberg/split_nlogo_experiment) .

${ }^{29}$ For a suitable relation between edges and nodes, we refer to Lämmer et al. (2006), who identified a ratio of 1 edge to 2.19 nodes for the city of Dortmund.

${ }^{30}$ Different seeds were used to ensure that differences between results depend on e.g. the edge composition.

${ }^{31}$ Each parameter combination was repeated twelve times in order to identify robust cases (i.e. at least ten out of twelve repetitions had to be within the predefined limits).

${ }^{32}$ This scenario has been developed in the DiscGo project (Governance of the discontinuation of socio-technical systems 2012-2015; cf. Hoffmann et al. 2017.

${ }^{33}$ More precisely, this controlling intervention represents a mixture of different road pricing measures, for example congestion charging or "bottleneck passage" (cf. Li \& Hensher 2012), emission pricing and cordon schemes. See Anas \& Lindsey (2011) for a detailed overview of different road pricing options.

\section{Acknowledgements}

Research has been funded by Deutsche Forschungsgemeinschaft 2012-2016 (WE 1581/5-1) under the title "Governance of the discontinuation of socio-technical systems" as well as by Fondation pour une culture de sécurité industrielle 2012-2016 (AO 2012-04) under the title "Mixed modes of governance as a means of risk management in complex systems".

\section{References}

Adelt, F., Weyer, J. \& Fink, R. D. (2014). Governance of complex systems: Results of a sociological simulation experiment. Ergonomics, 57(3), 434-448

Anas, A. \& Lindsey, R. (2011). Reducing urban road transportation externalities: Road pricing in theory and in practice. Review of Environmental Economics and Policy, 5(1), 66-88 
Banister, D. (2008). The sustainable mobility paradigm. Transport Policy, 15(2), 73-80

Cederman, L.-E. (1997). Emergent Actors in World Politics: How States and Nations Develop and Dissolve. Princeton, NJ: Princeton University Press

Chappin, E. J. L. \& Afman, M. R. (2013). An agent-based model of consumer lighting. In K. H. Van Dam, I. Nikolic \& Z. Lukszo (Eds.), Agent-Based Modelling of Socio-Technical Systems, (pp. 181-200). Dordrecht: Springer

City of Dortmund (2004). Flächennutzungsplan der Stadt Dortmund. Erläuterungsbericht. Retrieved from: http://www.dortmund.de/media/p/stadtplanungs_und_bauordnungsamt/stadtplanung_ bauordnung_downloads/stadtplanung_1/Erlbericht_DO_04_FNP.pdf .

Coleman, J. S. (1990). Foundations of Social Theory. Boston, MA: Harvard University Press

Coutard, O. (1999). The Governance of Large Technical Systems. London: Routledge

Dijk, M. \& Kemp, R. (2010). A framework for understanding product market innovation paths - Emergence of hybrid vehicles as an example. International Journal of Automotive Technology and Management, 10(1), 5676

District Government of Arnsberg (2017). Luftreinhalteplan Hagen 2017. Retrieved from https://www. bezreg-arnsberg.nrw.de/bekanntmachungen/2017/05/17_05_31_lrp_hagen/index.php

Duit, A., Galaz, V., Eckerberg, K. \& Ebbesson, J. (2010). Governance, complexity, and resilience. Global Environmental Change, 20(3), 363-368

Elster, J. (2016). Sour Grapes: Studies in the Subversion of Rationality. Cambridge: Cambridge University Press

Epstein, J. M. (2006). Generative Social Science: Studies in Agent-Based Computational Modeling. Princeton, NJ: Princeton University Press

Epstein, J. M. \& Axtell, R. (1996). Growing Artificial Societies: Social Science from the Bottom Up. Brookings Institution Press

Esser, H. (1993). The rationality of everyday behavior: A rational choice reconstruction of the theory of action by Alfred Schütz. Rationality and Society, 5(1), 7-31

Esser, H. (2000). Soziologie. Spezielle Grundlagen. Band 3: Soziales Handeln. Frankfurt am Main: Campus

European Parliament (2008). Directive 2008/50/EC of the European Parliament and of the Council of 21 May 2008 on ambient air quality and cleaner air for Europe. Retrieved from http://eur-lex.europa.eu/ legal-content/EN/TXT/?uri=celex\%3A32008L0050

Ghorbani, A., Bots, P., Dignum, V. \& Dijkema, G. (2013). MAIA: A framework for developing agent-based social simulations. Journal of Artificial Societies and Social Simulation, 16(2), 9

Gilbert, N. (2007). Computational social science: Agent-based social simulation. In D. Phan \& F. Amblard (Eds.), Agent-based Modelling and Simulation, (pp. 115-134). Oxford: Bardwell

Götz, K. (2007). Mobilitätsstile. In O. Schöller, W. Canzler \& A. Knie (Eds.), Handbuch Verkehrspolitik, (pp. 759784). Wiesbaden: VS Verlag

Grande, E. (2012). Governance-Forschung in der Governance-Falle? - Eine kritische Bestandsaufnahme. Politische Vierteljahresschrift, 53(4), 565-592

Grimm, V., Berger, U., Bastiansen, F., Eliassen, S., Ginot, V., Giske, J., Goss-Custard, J., Grand, T., Heinz, S. K., Huse, G., Huth, A., Jepsen, J. U., Jø rgensen, C., Mooij, W. M., Müller, B., Pe'er, G., Piou, C., Railsback, S. F., Robbins, A. M., Robbins, M. M., Rossmanith, E., Rüger, N., Strand, E., Souissi, S., Stillman, R. A., Vabø, R., Visser, U. \& DeAngelis, D. L. (2006). A standard protocol for describing individual-based and agent-based models. Ecological Modelling, 198(1), 115-126

Grimm, V., Berger, U., DeAngelis, D. L., Polhill, J. G., Giske, J. \& Railsback, S. F. (2010). The ODD protocol: A review and first update. Ecological Modelling, 221(23), 2760-2768

Grote, G. (2009). Management of Uncertainty. Theory and Application in the Design of Systems and Organizations. Berlin: Springer 
Helbing, D., Farkas, I. \& Vicsek, T. (2000). Simulating dynamical features of escape panic. Nature, 407(6803), 487

Hoffmann, S., Weyer, J. \& Longen, J. (2017). Discontinuation of the automobility regime? An integrated approach to multi-level governance. Transportation Research Part A: Policy and Practice, 103, 391-408

Horni, A., Nagel, K. \& Axhausen, K. W. (2016). The Multi-Agent Transport Simulation MATSim. London: Ubiquity Press

Jansen, D. \& Diaz-Bone, R. (2011). Netzwerkstrukturen als soziales Kapital. Konzepte und Methoden zur Analyse struktureller Einbettung. In J. Weyer (Ed.), Soziale Netzwerke. Konzepte und Methoden der sozialwissenschaftlichen Netzwerkforschung (2. Aufl.), (pp. 73-108). München: Oldenbourg

Köhler, J., Whitmarsh, L., Nykvist, B., Schilperoord, M., Bergman, N. \& Haxeltine, A. (2009). A transitions model for sustainable mobility. Ecological Economics, 68(12), 2985-2995

Konidari, P. \& Mavrakis, D. (2007). A multi-criteria evaluation method for climate change mitigation policy instruments. Energy Policy, 35(12), 6235-6257

Krajzewicz, D., Erdmann, J., Behrisch, M. \& Bieker, L. (2012). Recent development and applications of SUMOSimulation of Urban MObility. International Journal on Advances in Systems and Measurements, 5(3 \& 4)

Kron, T. (2006). Fuzzy-Logik für die Soziologie. Östereichische Zeitschrift für Soziologie, 30(3), 51-88

Kroneberg, C. (2014). Frames, scripts, and variable rationality: An integrative theory of action. In G. Manzo (Ed.), Analytical Sociology: Norms, Actions, and Networks, (pp. 97-123). Hoboken, NJ: Wiley

Krusch, C. (2008). Mikroökonomie in künstlichen Gesellschaften: vom Sugarscape zum Ruhrmodell. Münster: LIT Verlag

Lämmer, S., Gehlsen, B. \& Helbing, D. (2006). Scaling laws in the spatial structure of urban road networks. Physica A: Statistical Mechanics and its Applications, 363(1), 89-95

Latour, B. (2007). Eine Neue Soziologie für eine neue Gesellschaft - Einführung in die Akteur-Netzwerk-Theorie (A New Sociology for a New Society: An Introduction to Actor-Network-Theory). Frankfurt am Main: Suhrkamp

Li, Z. \& Hensher, D. A. (2012). Congestion charging and car use: A review of stated preference and opinion studies and market monitoring evidence. Transport Policy, 20, 47-61

Loorbach, D. (2007). Transition Management: New Mode of Governance for Sustainable Development. Utrecht: International Books

Lopolito, A., Morone, P. \& Taylor, R. (2013). Emerging innovation niches: An agent based model. Research Policy, 42(6-7), 1225-1238

Lürwer, M. \& Meißner, A. (2013). Haushaltsbefragung zum mobilitätsverhalten der dortmunder bevölkerung. Retrieved from: http://www.dortmund.de/media/p/stadtplanungs_und_bauordnungsamt/ stadtplanung_bauordnung_downloads/verkehrsplanung/Vorlage_Mobilitaetsverhalten.pdf

Mallig, N., Kagerbauer, M. \& Vortisch, P. (2013). mobiTopp - A modular agent-based travel demand modelling framework. Procedia Computer Science, 19(C), 854-859

Meißner, A. (2014). Haushaltsbefragung zum Mobilitätsverhalten der Dortmunder Bevölkerung 2013. Retrieved from: https://www.dortmund.de/de/leben_in_dortmund/planen_bauen_wohnen/stadtplanungs_ und_bauordnungsamt/stadtplanung/verkehrsplanung/gesamtstaedtische_verkehrsplanung/ haushaltsbefragung_mobi/index.html

Mueller, M. G. \& de Haan, P. (2009). How much do incentives affect car purchase? Agent-based microsimulation of consumer choice of new cars - Part i: Model structure, simulation of bounded rationality, and model validation. Energy Policy, 37(3), 1072-1082

Nagel, K. \& Schreckenberg, M. (1992). A cellular automaton model for freeway traffic. Journal de Physique I, 2(12), 2221-2229

Ostrom, E. (2010). Beyond markets and states: Polycentric governance of complex economic systems. American Economic Review, 100(3), 641-72 
Papachristos, G. (2014). Towards multi-system sociotechnical transitions: Why simulate. Technology Analysis \& Strategic Management, 26(9), 1037-1055

Resnick, M. (1995). Turtles, Termites, and Traffic Jams: Explorations in Massively Parallel Microworlds. Cambridge, MA: Mit Press

Schlüter, M., Baeza, A., Dressler, G., Frank, K., Groeneveld, J., Jager, W., Janssen, M. A., McAllister, R. R., Müller, B., Orach, K., Schwarz, N. \& Wijermans, N. (2017). A framework for mapping and comparing behavioural theories in models of social-ecological systems. Ecological Economics, 131, 21-35

Selten, R., Chmura, T., Pitz, T., Kube, S. \& Schreckenberg, M. (2007). Commuters route choice behaviour. Games and Economic Behavior, 58(2), 394-406

Shove, E. (2004). Sustainability, system innovation and the laundry. In B. Elzen, F. Geels \& K. Green (Eds.), System Innovation and the Transition to Sustainability: Theory, Evidence and Policy, (pp. 76-94). Cheltenham: Elgar

Stonedahl, F. \& Wilensky, U. (2008). Netlogo diffusion on a directed network model. Retrieved from Evanston, IL.: http://ccl.northwestern.edu/netlogo/models/DiffusiononaDirectedNetwork

Stonedahl, F. \& Wilensky, U. (2009). Netlogo pagerank model. Retrieved from Evanston, IL.: http://ccl. northwestern.edu/netlogo/models/PageRank

Teigelkamp, T. (2015). Verkehrsmittelwahl als Thema der soziologischen Handlungstheorie. Eine empirische Studie. Bachelorthesis. TU Dortmund, Dortmund. Technology Studies Group

The Guardian (2017). Oslo temporarily bans diesel cars to combat pollution. Retrieved from https://www.theguardian.com/environment/2017/jan/16/ oslo-temporarily-bans-diesel-cars-combat-pollution

Torfing, J., Peters, B. G., Pierre, J. \& Sø rensen, E. (2012). Interactive Governance: Advancing the Paradigm. Oxford: Oxford University Press

Transport for London (2017). T-charge: Emissions surcharge. Retrieved from https://tfl.gov.uk/modes/ driving/emissions-surcharge

Van Dam, K. H., Nikolic, I. \& Lukszo, Z. (2013). Agent-Based Modelling of Socio-Technical Systems. Dordrecht: Springer

Velasquez, M. \& Hester, P. T. (2013). An analysis of multi-criteria decision making methods. International Journal of Operations Research, 10(2), 56-66

Weyer, J., Adelt, F. \& Hoffmann, S. (2015). Governance of socio-technical systems. A multi-level model. Soziologisches Arbeitspapier der TU Dortmund, 42

Wilensky, U. (1999). NetLogo. Center for Connected Learning and Computer-Based Modeling, Northwestern University

Wilensky, U. (2007). Link-walking turtles example. Retrieved from http://ccl.northwestern.edu/netlogo

Willke, H. (2007). Smart Governance: Governing the Global Knowledge Society. Frankfurt am Main: Campus 